Org Lett. 2016 October 07; 18(19): 4880-4883. doi:10.1021/acs.orglett.6b02320.

\title{
Stereoselective Multicomponent Reactions Using Zincate Nucleophiles: $\beta$-Dicarbonyl Synthesis and Functionalization
}

\author{
Stephen K. Murphy ${ }^{\dagger}$, Mingshuo Zeng ${ }^{\dagger}$, Seth B. Herzon ${ }^{\star}, \dagger, \ddagger$ \\ tDepartment of Chemistry, Yale University, New Haven, Connecticut 06520, United States \\ ‡Department of Pharmacology, Yale School of Medicine, New Haven, Connecticut 06520, United \\ States
}

\begin{abstract}
A general strategy for conjugate addition- $C$-acylation that enables the synthesis of enantioenriched $\beta$-dicarbonyl compounds is described. A novel method for derivatizing these adducts by stereo- and site-selective zinc-catalyzed addition of alkyllithium reagents is also reported. These reactions can be performed in tandem to achieve an enantio- and diastereoselective four-component coupling. The in situ generation of weakly basic lithium zincate species is central to the success of all three transformations.
\end{abstract}

\section{Graphical Abstract}

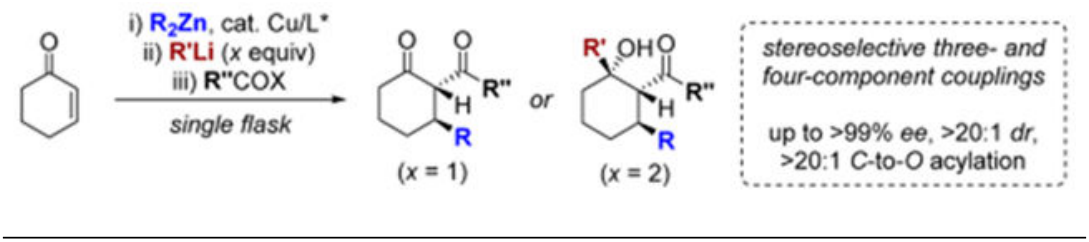

\begin{abstract}
Multicomponent reactions rapidly increase molecular complexity, allowing improvements in synthetic efficiency. ${ }^{1}$ The conjugate addition of an organometallic reagent to an enone followed by trapping of the resulting enolate with an aldehyde (the Noyori three-component coupling, Figure 1A, top) exemplifies the power of such transformations to affect strategic fragment couplings. ${ }^{2}$ The ability to access ketone enolates with regiocontrol is a noteworthy element of this strategy. However, the related sequence involving 1,4-addition and enolate $C$ acylation is conspicuously underdeveloped (Figure 1A, bottom). ${ }^{2 \mathrm{~b}, 3}$ As noted in a review, “...conjugate addition-enolate acylation reactions are very substrate dependent. With certain substrates, $O$-acylation competes or even predominates despite the use of conditions conducive to reaction at carbon." $2 \mathrm{~b}$ Competitive proton transfer from the $\beta$-dicarbonyl product to the enolate can also occur, which leads to $C, O$-diacylated and nonacylated
\end{abstract}

\footnotetext{
*Corresponding Author: seth.herzon@yale.edu.

Supporting Information

The Supporting Information is available free of charge on the ACS Publications website at DOI: 10.1021/acs.orglett.6b02320.

Experimental procedures and characterization data (PDF)

The authors declare no competing financial interest.
} 
products. $^{2 \mathrm{~b}, 3 \mathrm{c}}$ Consequently, reliable methods for $\beta$-diketone synthesis by a three-component coupling strategy have been elusive, and enantioselective variants are unknown. ${ }^{4}$

Herein, we report the first general strategy for affecting enantio- and diastereoselective 1,4addition- $C$-acylation reactions (Figure 1B). Key to its success is the use of in situ generated zincate enolates that are highly nucleophilic at carbon but weakly basic. ${ }^{5}$ This reaction yields $C$-acylated products irrespective of the nucleophile, enone, or acylating reagent employed. Furthermore, we have leveraged the power of this sequence to develop a fourcomponent coupling that sets three contiguous stereocenters with absolute and relative stereocontrol (Figure 1C). This transformation combines 1,4-addition- $C$-acylation with a novel 1,2-addition of zincates to $\beta$-diketones. As shown, the latter transformation can also be performed independently using zinc catalysis.

To control the absolute stereochemistry of 1,4-addition, we employed Feringa's phosphoramidite-based method, which is among the most general and reliable for stereoselective 1,4-addition of organozinc reagents to enones. ${ }^{4 a, 6}$ As shown in Scheme 1, direct trapping of the resulting methylzinc enolate with acetyl chloride was inefficient and provided the $C-, O$, and diacylated products $\mathbf{2 a - 4 a}$ in $11-36 \%$ yields. ${ }^{7,8}$ We hypothesized that this methylzinc enolate could be activated by the addition of a second nucleophile to form an ate complex in situ. Noyori's finding that the lithium enolate of cyclohexanone undergoes $C$-acylation after activation with dimethylzinc provided an important precedent. ${ }^{5 \mathrm{a}}$ Indeed, a dramatic increase in reactivity and regioselectivity was observed when methyllithium (1.05 equiv) was added immediately before the acylating reagent. ${ }^{9}$ The resulting lithium dimethylzincate enolate was rapidly $C$-acylated at $-78{ }^{\circ} \mathrm{C}$ to provide the 1,3-dicarbonyl $\mathbf{2 a}$ in $80 \%$ isolated yield. The $O$-acylated and diacylated products $\mathbf{3 a}$ and $\mathbf{4 a}$ were not detected by ${ }^{1} \mathrm{H}$ NMR or GC-MS analysis.

This three-component coupling is general and provides access to an array of stereochemically defined 1,3-diketones (Scheme 2). In all cases examined, exclusive $C$ acylation was observed irrespective of the organozinc reagent, enone, or acid chloride employed. Furthermore, all products were generated in $>90 \%$ ee, and only the trans diastereomers were formed, although the products 2a-g,n,o exist partially as their enol tautomers. In agreement with Feringa's report on the 1,4-addition of organozinc reagents to enones, ${ }^{4 \mathrm{a}}$ the absolute configuration of $\mathbf{2} \mathbf{j}$ was established to be $2 S, 3 S$ on the basis of singlecrystal X-ray analysis. ${ }^{10}$ Unhindered or electron-deficient aliphatic acid chlorides underwent acylation rapidly at $-78^{\circ} \mathrm{C}(\mathbf{2 a - d})$, while warming to $0{ }^{\circ} \mathrm{C}$ was necessary when more hindered electrophiles, such as isobutyryl chloride (2g), were employed. Sterically and electronically diverse aroyl chlorides were excellent substrates for this reaction. Although certain aroyl chlorides displayed reactivity in the absence of methyllithium, the yields and selectivities were diminished in those instances. ${ }^{11}$ Esters (2q), anisoles (2p), benzyl ethers (2d), aryl chlorides (2o), ortho-substitution ( $\mathbf{2 n}$ and $\mathbf{2 0}$ ), and proximal quaternary centers (2m) were all compatible with this sequence. Furthermore, the method is applicable to mediumsized enones such as 2-cyclohepten-1-one and 2-cycloocten-1-one (products $\mathbf{2 k}$ and 2I). In contrast to analogous reactions with organocopper reagents, ${ }^{3}>20: 1 C$-selectivity was maintained with a variety of $\beta$-substituents $(\mathbf{2} \mathbf{a}-\mathbf{c}, \mathbf{h}-\mathbf{j})$. 
The scope of this reaction includes a range of carbonyl electrophiles (Table 1).

Chloroformates, cyanoformates, ${ }^{13}$ anhydrides, and benzoyl fluorides provided the corresponding addition-acylation products in $48-73 \%$ yields (entries 1-4). It is noteworthy that chloroformates and anhydrides typically provide $O$-acylated products when reacted with a variety of metalloenolates, ${ }^{2 b, 14,15}$ and in the absence of activation, monoalkylzinc enolates were completely unreactive toward chloroformates and cyanoformates (entries 1 and 2). The reaction was readily performed on a $21 \mathrm{mmol}$ scale using Mander's reagent as the electrophile (entry 2).

The $\beta$-dicarbonyl compounds accessed in this study can be converted to other stereochemically complex products. For example, ketoester $\mathbf{2 s}$ undergoes diastereoselective $C$-alkylation on treatment with iodomethane and sodium tert-butoxide (Scheme 3, eq 1).

Based on our finding that zincate enolates are nonbasic nucleophiles useful in $\beta$-dicarbonyl synthesis, we considered that trialkylzincates might be ideal nucleophiles for 1,2-addition to enolizable $\beta$-dicarbonyls. Existing methods for the 1,2-addition of organometallic reagents to $\beta$-diketones employ stoichiometric amounts of cerium trichloride or excess Grignard reagents with heating. ${ }^{16}$ By comparison, we found that the addition could be carried out efficiently using substoichiometric amounts of $\mathrm{ZnCl}_{2}(10 \mathrm{~mol} \%)$ and 1.25 equiv of methyllithium (Scheme 3, eq 2). We believe that methyllithium reacts rapidly with the zinc salt leading to in situ formation of the triorganozincate. ${ }^{17}$ In the absence of zinc chloride, 1,2 -addition products are formed in only $25 \%$ yield as mixtures of regioisomers and diastereomers. Treating $\mathbf{2 h}$ with preformed $\mathrm{LiZn}\left(\mathrm{CH}_{3}\right)_{3}$ led to the $\beta$-hydroxy ketone $\mathbf{6 a}$ in $98 \%$ yield as a single isomer, supporting the intermediacy of a triorganozincate in the zinccatalyzed process.

This zinc-catalyzed 1,2-addition is applicable to a variety of enolizable cyclic and acyclic $\beta$ diketones (Scheme 4). Using the products derived from conjugate addition- $C$-acylation, the cyclic dialkyl ketone substituent undergoes addition in preference to the aryl ketone ( $>20: 1$ regioselectivity). The high stereo- and regioselectivity are maintained for substrates with varying steric bulk at the $\beta$-position (6a-c). While yields were excellent for electron-neutral and electron-rich $\beta$-diketones (6a-d), substrates with electron-withdrawing substituents provided low yields of product $(30 \%, \mathbf{6 e})$, potentially due to competitive proton transfer. Distinct regioselectivity was observed when acyclic $\beta$-diketones were employed. In these instances, the zincate underwent selective addition to the aryl ketone in preference to the dialkyl ketone and the selectivity improved when bulkier substrates were employed ( $\mathbf{6} \mathbf{f}-\mathbf{h})$.

Stereochemical models for the 1,2-addition of zincates to diketones are depicted in Scheme 5 . Given the high levels of stereoselectivity obtained when either cyclic or acyclic substrates are used, we suggest that the $\beta$-diketones chelate to a lithium cation leading to a rigid transition state. ${ }^{18}$ In the case of acyclic substrates, syn-pentane interactions force the alkyl backbone of the molecule into an extended conformation that increases the steric demand around the dialkyl ketone. Thus, addition occurs to the aryl ketone from the face opposite the $a$-substituent. The regioselectivity is reversed for cyclic substrates. In these instances, the substituents on the dialkyl ketone are constrained by the ring, rendering that carbonyl more accessible. Furthermore, nucleophilic addition to the aryl ketone would generate syn-pentane interactions between the $\beta$-alkyl substituent and either the aryl group or incoming 
nucleophile. Accordingly, equatorial attack of the zincate on the cyclohexanone occurs to produce the observed stereoisomer.

Finally, we discovered that this method can be modified to affect a one-flask asymmetric four-component coupling (Scheme 6). By increasing the amount of methyllithium used to activate the zinc enolate from 1.05 to 2.05 equiv, the $\beta$-hydroxy ketone $\mathbf{6 a}$ was obtained in $54 \%$ yield as a single detectable diastereomer and in $96 \%$ ee. The yield was improved to $61 \%$ when methylmagnesium bromide was used as the activator and products $\mathbf{6 i}, \mathbf{j}$ were synthesized using alternative acid chlorides and organolithium reagents. This fourcomponent coupling forges three $\mathrm{C}-\mathrm{C}$ bonds and sets three contiguous stereocenters.

In summary, we have developed a general method for the stereoselective addition of organozinc reagents to $a, \beta$-unsaturated ketones followed by high-yielding acylation of the resulting enolates. This fundamental sequence provides stereo- and regiocontrolled access to 1,3-dicarbonyl products and closes a long-standing gap in the methodological literature. The products are useful precursors to other complex products via site- and stereoselective $C$ alkylation or zinc-catalyzed alkylation. Key to the success of these strategies was the use of zincate nucleophiles which undergo chemo-, regio-, and diastereoselective addition reactions while avoiding competitive proton transfers from acidic 1,3-dicarbonyl functional groups. This strategy is applicable to a wide range of enones, organozinc reagents, and carboxylic acid derivatives, and the use of these methods in multistep synthesis is currently ongoing.

\section{Supplementary Material}

Refer to Web version on PubMed Central for supplementary material.

\section{ACKNOWLEDGMENTS}

Financial support from Yale University, the National Institute of General Medical Sciences (R01GM090000), and the National Sciences and Engineering Research Council of Canada (postdoctoral fellowship to S.K.M.) is gratefully acknowledged. We thank Dr. Brandon Mercado for X-ray crystallographic analysis.

\section{REFERENCES}

(1). For a review, see:Touré BB; Hall DG Chem. Rev 2009, 109, 4439. [PubMed: 19480390]

(2). (a)Noyori R; Suzuki M Angew. Chem., Int. Ed. Engl 1984, 23, 847.For general reviews on conjugate addition-enolate functionalization reactions, see:(b)Taylor RJK Synthesis 1985, 364. (c)Kim JH; Ko YO; Bouffard J; Lee S.-g. Chem. Soc. Rev 2015, 44, 2489. [PubMed: 25708795]

(3). For selected examples of 1,4-addition of organocopper reagents, followed by acylation, see: (a)Tanaka T; Kurozumi S; Torn T; Kobayashi M; Miura S; Ishimoto S Tetrahedron Lett. 1975, 16, 1535.(b)Tanaka T; Kurozumi S; Toru T; Kobayashi M; Miura S; Ishimoto S Tetrahedron 1977, 33, 1105.(c)Bernasconi S; Gariboldi P; Jommi G; Sisti M Tetrahedron Lett. 1980, 21, 2337.

(4). Related strategies for accessing enantioenriched 1,3-dicarbonyl compounds have been reported. For the tandem conjugate addition-aldol reaction followed by PCC oxidation of the resulting $\beta$ hydroxy ketones, see:(a)Feringa BL; Pineschi M; Arnold LA; Imbos R; de Vries AHM Angew. Chem., Int. Ed. Engl 1997, 36, 2620.For the enantioselective conjugate addition of organozinc reagents to $a$-acyl enones, see:(b)Tang X; Blake AJ; Lewis W; Woodward S Tetrahedron: Asymmetry 2009, 20, 1881.

(5). For selected examples of applications of zincate enolates, see:(a)Morita Y; Suzuki M; Noyori R J. Org. Chem 1989, 54, 1785.(b)Uchiyama M; Kameda M; Mishima O; Yokoyama N; Koike M; Kondo Y; Sakamoto T J. Am. Chem. Soc 1998, 120, 4934.(c)Dudley GB; Engel DA; Ghiviriga I; 
Lam H; Poon KWC; Singletary JA Org. Lett 2007, 9, 2839. [PubMed: 17583345] (d)Tomita Y; Ichikawa Y; Itoh Y; Kawada K; Mikami K Tetrahedron Lett. 2007, 48, 8922.

(6). For a complementary approach to enantioselective addition of organozinc reagents to enones, see:Degrado SJ; Mizutani H; Hoveyda AH J. Am. Chem. Soc 2001, 123, 755. [PubMed: 11456598]

(7). Related alkylzinc enolates have been trapped intermolecularly by aldehydes, oxycarbenium ions, allylic electrophiles, and silylating agents, see:(a)Naasz R; Arnold LA; Pineschi M; Keller E; Feringa BL J. Am. Chem. Soc 1999, 121, 1104.(b)Alexakis A; Trevitt GP; Bernardinelli G J. Am. Chem. Soc 2001, 123, 4358. [PubMed: 11457212] (c)Knopff O; Alexakis A Org. Lett 2002, 4, 3835. [PubMed: 12599471] (d)Dijk EW; Panella L; Pinho P; Naasz R; Meetsma A; Minnaard AJ; Feringa BL Tetrahedron 2004, 60, 9687.For intramolecular reactions, see:(e)Agapiou K; Cauble DF; Krische MJ J. Am. Chem. Soc 2004, 126, 4528. [PubMed: 15070365]

(8). Acylation of the zinc enolate derived from ethyl tert-butyl ketone with benzoyl chloride has been reported to occur in 65\% yield, see:Hansen MM; Bartlett PA; Heathcock CH Organometallics 1987, 6, 2069.The rhodium-catalyzed acylation of zinc enolates with aroyl chlorides has also been reported, see:Sato K; Yamazoe S; Yamamoto R; Ohata S; Tarui A; Omote M; Kumadaki I; Ando A Org. Lett 2008, 10, 2405. [PubMed: 18476711]

(9). Other organometallic reagents, such as methylmagnesium bromide, $n$-butyllithium, phenyllithium, and vinyllithium, can be used to promote $C$-acylation.

(10). The data for $\mathbf{2} \mathbf{j}$ has been deposited to the CCDC (ref no. CCDC 1503495).

(11). See the Supporting Information for comparisons.

(12). Bartlett SL; Beaudry CM J. Org. Chem 2011, 76, 9852. [PubMed: 22023037]

(13). During the preparation of this manuscript, a related procedure for the conjugate addition of dimethylzinc to 2-cyclohexen-1-one and acylation with Mander's reagent was employed in the asymmetric total synthesis of amphilectane and serrulatane natural products, see:Yu X; Su F; Liu C; Yuan H; Zhao S; Zhou Z; Quan T; Luo T J. Am. Chem. Soc 2016, 138, 6261. [PubMed: 27115064]

(14). May TL; Dabrowski JA; Hoveyda AH J. Am. Chem. Soc 2011, 133, 736. [PubMed: 21171599]

(15). Vuagnoux-d'Augustin MV; Alexakis A Tetrahedron Lett. 2007, 48, 7408.

(16). (a)Bartoli G; Marcantoni E; Petrini M Angew. Chem., Int. Ed. Engl 1993, 32, 1061.(b)Yuan R; Zhao D; Zhang L-Y; Pan X; Yang Y; Wang P; Li H-F; Da C-S Org. Biomol. Chem 2016, 14, 724. [PubMed: 26575990] (c)Leighton and co-workers developed a method for the enantioselective allylation of diketones using a chiral allylsilane reagent, see: Chalifoux W; Reznik SK; Leighton JL Nature 2012, 487, 86. [PubMed: 22763452]

(17). Hatano M; Suzuki S; Ishihara K J. Am. Chem. Soc 2006, 128, 9998. [PubMed: 16881613]

(18). Lower yields were obtained when the reaction was conducted in tetrahydrofuran, perhaps due to interfere with the formation of chelated intermediates. 
A. Multi-component reactions involving 1,4-addition and enolate trapping

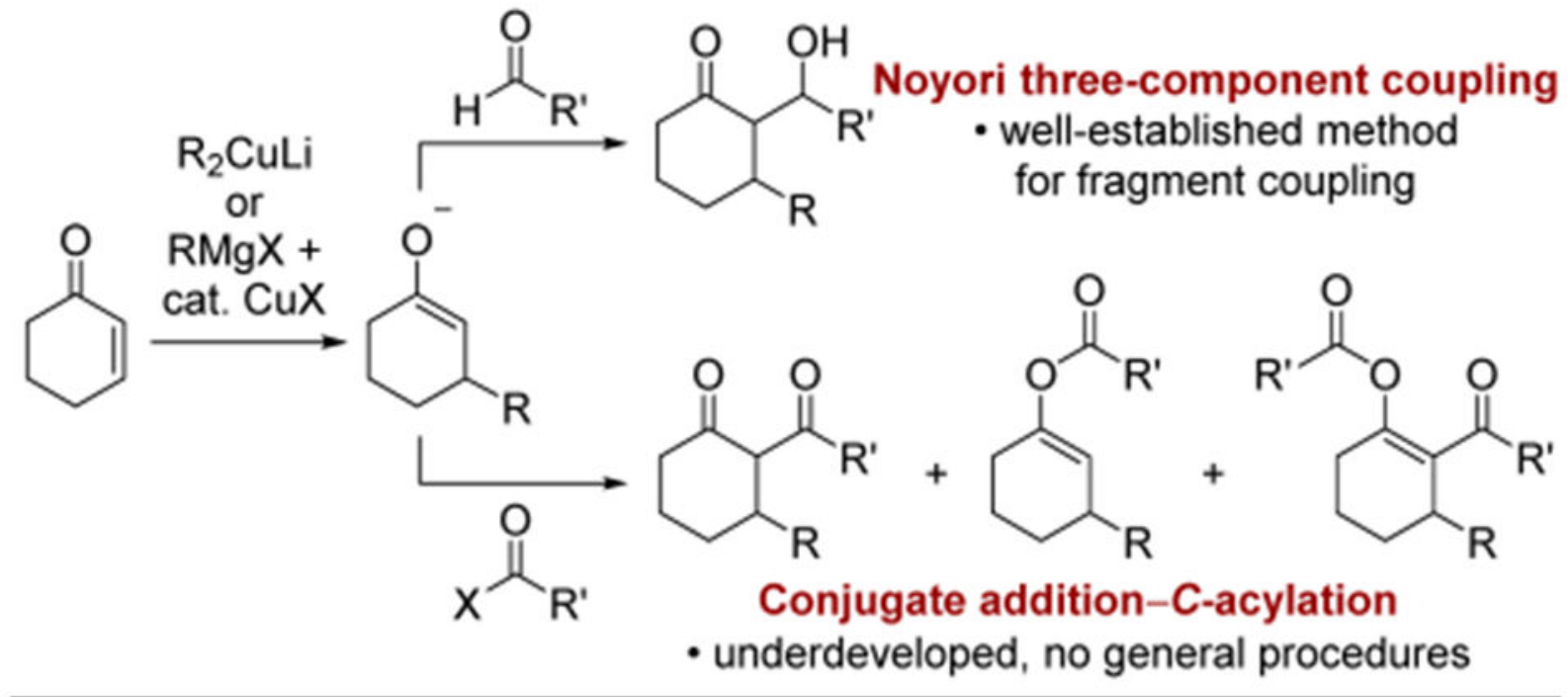

B. Organozincate enolates for conjugate addition-C-acylation

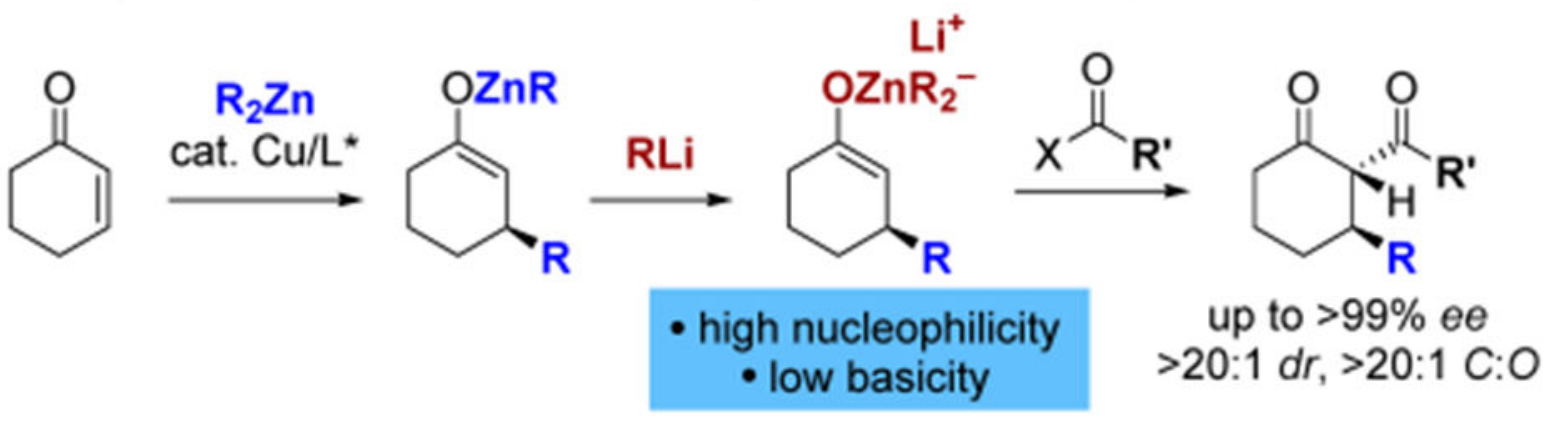

C. Asymmetric four-component coupling<smiles>O=C1C=CCCC1</smiles>

i) $\mathbf{R}_{2} \mathrm{Zn}$, cat. $\mathrm{Cu} / \mathrm{L}^{*}$

ii) R'Li (2 equiv)

iii) $R^{\prime \prime C O X}$<smiles>[R]C(=O)[C@]1(O)C([R])CCC[C@@]1([R])O</smiles>

up to $96 \%$ ee, $>20: 1 d r$

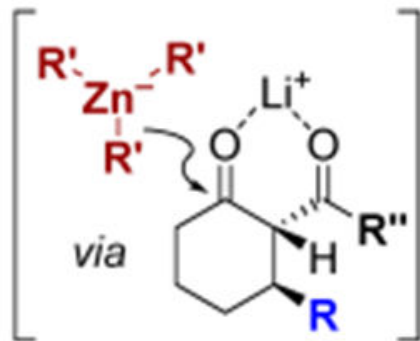

Figure 1.

(A) Tandem conjugate addition-acylation is highly substrate dependent. (B) Strategy for tandem conjugate addition-acylation exploiting the activation of zinc enolates with organolithium reagents. (C) Four-component coupling to establish three contiguous stereocenters in a single flask. 
<smiles>CC(=O)OC1=C[C@H](C)CCC1OC(C)=O</smiles><smiles>C[C@@H](c1ccccc1)N([C@H](C)c1ccccc1)P(Oc1ccccc1)Oc1ccc2ccccc2c1-c1ccccc1</smiles>

\section{acylating conditions}

$\mathrm{CH}_{3} \mathrm{COCl}, 0^{\circ} \mathrm{C}$ to $22^{\circ} \mathrm{C}, 4 \mathrm{~h}$

$\mathrm{CH}_{3} \mathrm{Li},-78^{\circ} \mathrm{C}, 1 \mathrm{~min}$ then $\mathrm{CH}_{3} \mathrm{COCl},-78^{\circ} \mathrm{C}, 15 \mathrm{~min}$
$2 a(\%) \quad 3 a(\%) \quad 4 a(\%)$

36 12

$80<1<1$

Scheme 1.

Reactivity of Alkylzinc Enolates and Lithium Dialkylzincate Enolates 


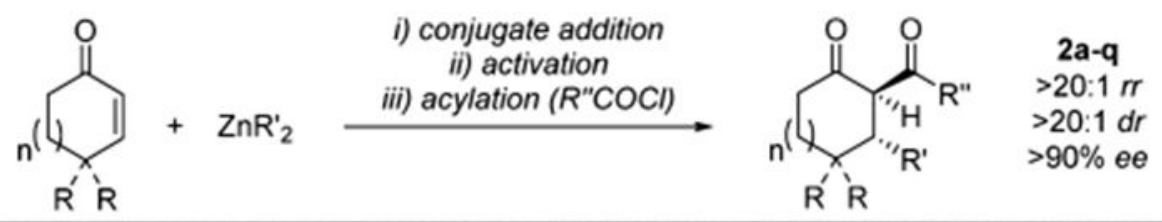<smiles>CC(=O)C1C(=O)CCC[C@H]1C</smiles>

2a: $80 \%^{\mathrm{b}}$ $96 \%$ ee<smiles>C[C@@H]1CCCC(=O)[C@H]1C(=O)CBr</smiles>

2e: $85 \%$ $96 \%$ ee<smiles>CC[C@H]1CCCC(=O)C1(C(=O)c1ccccc1)C(=O)c1ccccc1</smiles>

2i, $76 \%$ $94 \%$ ee<smiles>CC[C@H]1CCCC(=O)[C@]1(C)C(C)=O</smiles>

2b: $75 \%$ $94 \%$ ee<smiles>CC(C)CC(=O)[C@H]1C(=O)CCC[C@H]1C</smiles>

2f: $70 \%$, $96 \%$ ee<smiles>CC(C)[C@H]1CCCC(=O)[C@H]1C(=O)c1ccccc1</smiles>

2j, $56 \%$ $90 \%$ ee<smiles>CC(=O)[C@H]1C(=O)CCC[C@H]1C(C)C</smiles>

2c: $83 \%^{\mathrm{b}}$ $90 \%$ ee<smiles>C[C@@H]1CCCC(=O)[C@H]1C(=O)COCc1ccccc1</smiles>

2d: $82 \%^{b}$

$96 \%$ ee<smiles>CC(C)C(=O)[C@]1(C)C(=O)CCC[C@H]1C</smiles>

2g: $61 \%$ $96 \%$ ee<smiles>C[C@H]1CCCCC(=O)[C@H]1C(=O)c1ccccc1</smiles>

2k: $76 \%$ $94 \%$ ee<smiles>C[C@@H]1CCCC(=O)[C@]1(C)C(=O)c1ccccc1</smiles>

2h, $81 \%$ $96 \%$ ee<smiles>C[C@H]1CCCCCC(=O)C1(C(=O)c1ccccc1)C(=O)c1ccccc1</smiles>

2l: $36 \%\left(56 \%{ }^{*}\right)$ $98 \%$ ee<smiles>C[C@H]1[C@H](C(=O)c2ccccc2)C(=O)CCC1(C)C</smiles><smiles>Cc1ccccc1C(=O)[C@@]1(C)C(=O)CCC[C@@H]1C</smiles><smiles>C[C@@H]1CCCC(=O)[C@]1(C(=O)O)C(=O)c1ccccc1Cl</smiles><smiles>COc1ccc(C(=O)[C@H]2C(=O)CCC[C@H]2C)cc1</smiles>

2p: $76 \%$

$96 \%$ ee<smiles>COC(=O)c1ccc(C(=O)[C@@H]2C(=O)CCC[C@H]2C)cc1</smiles>

2q: $74 \%$

$96 \%$ ee

Scheme 2. Scope of the 1,4-Addition-Acylation Sequence ${ }^{a}$

${ }^{a}$ General conditions: $\mathrm{R}_{2} \mathrm{Zn}$ (1.05 equiv), $\mathrm{Cu}(\mathrm{OTf})_{2}(2 \mathrm{~mol} \%), \mathrm{L} *(4 \mathrm{~mol} \%), \mathrm{Et}_{2} \mathrm{O},-30$ to $0{ }^{\circ} \mathrm{C}, 0.5-5 \mathrm{~h}$, then $\mathrm{CH}_{3} \mathrm{Li}$ ( 1.05 equiv), $-78^{\circ} \mathrm{C}, 1-5 \mathrm{~min}$, then acid chloride (1.2 equiv), -78 to $0{ }^{\circ} \mathrm{C}, 15 \mathrm{~min}-3 \mathrm{~h}$. In general, isolated yields were 5-15\% lower than NMR yields due to decomposition of diketones on silica gel. This phenomenon has been noted by others. ${ }^{12}$ Instances where the isolated yields and NMR yields differed by $>20 \%$ are denoted with an asterisk. ${ }^{b}$ Average of two runs.

Org Lett. Author manuscript; available in PMC 2020 February 04. 
<smiles>COC(=O)[C@H]1C(=O)CCC[C@@H]1C</smiles>

$\mathrm{CH}_{3} \mathrm{I}, \mathrm{CH}_{3} \mathrm{OH}, t \mathrm{BuONa}$

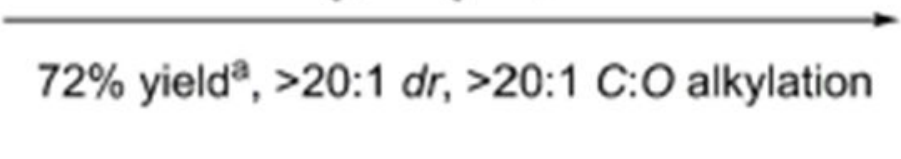<smiles>COC(=O)[C@]1(C)C(=O)CCC[C@H]1C</smiles><smiles>C[C@H]1CCCC(=O)[C@@H]1C(=O)c1ccccc1</smiles>

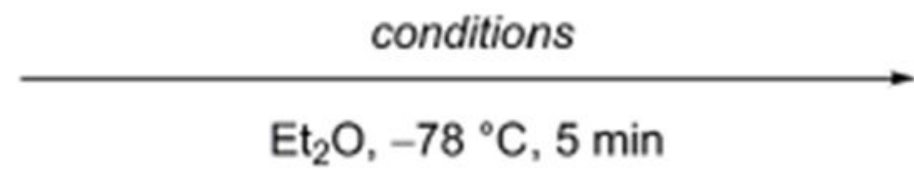

2h<smiles>C[C@H]1CCC[C@@H](O)[C@H]1C(=O)c1ccccc1</smiles>

$$
\begin{array}{cccc}
\text { conditions } & \text { yield (\%) } & \boldsymbol{d} \boldsymbol{r} & \boldsymbol{r r} \\
\mathrm{CH}_{3} \mathrm{Li}\left(1.25 \text { equiv), } \mathrm{ZnCl}_{2}(10 \mathrm{~mol} \%)\right. & 95 & >20: 1 & >20: 1 \\
\mathrm{CH}_{3} \mathrm{Li}(1.05 \text { equiv) } & 25 & 1: 1.3 & 1: 2 \\
\mathrm{CH}_{3} \mathrm{MgBr}(1.05 \text { equiv) } & 20 & >20: 1 & 1: 2.5 \\
\mathrm{Li}^{+} \mathrm{Zn}\left(\mathrm{CH}_{3}\right)_{3}{ }^{-} \text {(1.05 equiv) } & 98 & >20: 1 & >20: 1
\end{array}
$$

Scheme 3. $\boldsymbol{C}$-Alkylation and Nucleophilic Addition

${ }^{a}$ Yield over two steps (conjugate addition-acylation and $C$-alkylation). 
<smiles>[R]C(=O)C([R2])C([R])=O</smiles><smiles>CCO[Pb]S[Sb]</smiles><smiles>[R]C(=O)C([R2])[C@]([R])(C)O</smiles><smiles>C[C@H]1CCC[C@@H](C)[C@H]1C(=O)c1ccccc1</smiles>

6a, $95 \%$

$>20: 1 d r$

$>20: 1 \mathrm{rr}$<smiles>CCC(=O)[C@H](C)[C@H](O)c1ccccc1</smiles>

6f, $60 \%$

7.3:1 dr

6:1 rr<smiles>CC[C@H]1CCC[C@@H](O)C1(C(=O)c1ccccc1)C(=O)c1ccccc1</smiles>

6b, $94 \%$

$>20: 1 d r$

$>20: 1 \mathrm{rr}$<smiles>CC(C)C(=O)[C@H](C)[C@](C)(O)c1ccccc1</smiles>

$6 \mathrm{~g}, 70 \%$

8:1 dr

$>20: 1 r r$<smiles>CC(C)[C@H]1CCC[C@@H](O)[C@]1(C(=O)c1ccccc1)C(C)C</smiles>

6c, $85 \%$

$>20: 1 d r$ $>20: 1 \mathrm{rr}$<smiles>COc1ccc(C(=O)[C@H]2[C@@H](C)CCC[C@H]2C)cc1</smiles>

6d, $81 \%$ $>20: 1 d r$ $>20: 1 r r$<smiles>C[C@H](C(=O)C(C)(C)C)[C@@H](O)c1ccccc1</smiles>

$6 h, 88 \%$

13:1 dr

$>20: 1 \mathrm{rr}$<smiles>COC(=O)c1ccc(C(=O)[C@H]2[C@@H](C)CCC[C@@H]2O)cc1</smiles>

6e, $30 \%$ $>20: 1 d r$ $>20: 1 r r$

Scheme 4.

Scope of $\mathrm{ZnCl}_{2}$-Catalyzed Addition of Methyllithium to $\beta$-Diketones 
acyclic $\beta$-diketones

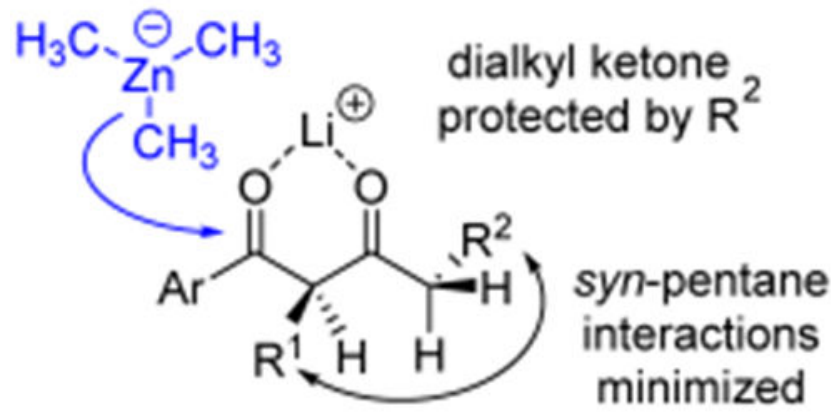

\section{cyclic $\beta$-diketones}

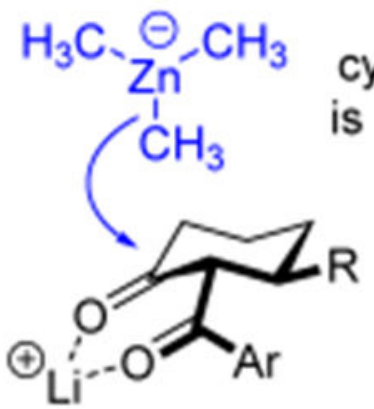

cyclic structure

is less hindered

aryl ketone protected by $\mathrm{R}$ via syn-pentane interactions

Scheme 5.

Stereochemical Models for 1,2-Additions to Ketones with Zincate Nucleophiles 
<smiles>O=C1C=CCCC1</smiles>

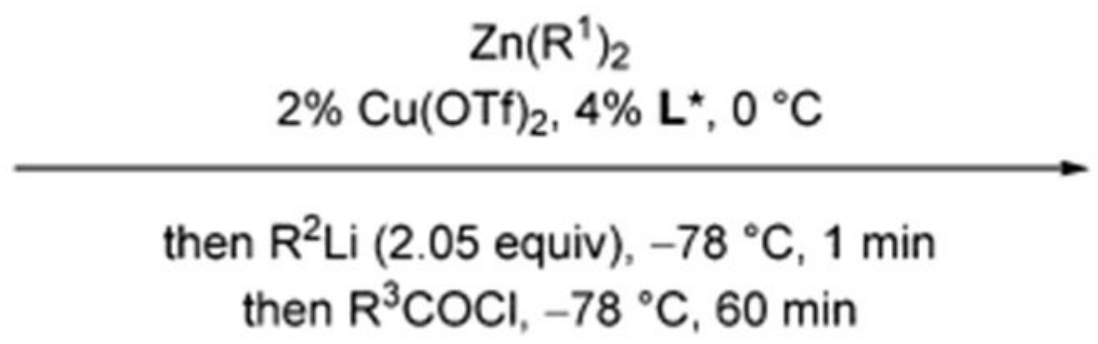<smiles>[R]C(=O)[C@]1(O)C([R2])CCC[C@]1([R2])O</smiles>

6a, i, j<smiles>C[C@@H]1CCC[C@@H](O)[C@H]1C(=O)c1ccccc1</smiles>

6a, $54 \%\left(61 \%^{a}\right)$ $>20: 1 d r, 96 \%$ ee<smiles>CCCCC(=O)[C@H]1[C@@H](C)CCC[C@H]1C</smiles>

6i, $50 \%$ $>20: 1 d r, 96 \%$ ee<smiles>C=C[C@]1(O)CCC[C@H](CC)[C@H]1C(=O)c1ccccc1</smiles>

6j, $54 \%$ $>20: 1 d r, 94 \%$ ee

Scheme 6. Four-Component Coupling Reactions

${ }^{a}$ Methylmagnesium bromide used instead of methyllithium. 
Table 1.

Scope of the Carbonyl Electrophile in the Asymmetric Conjugate Addition-Acylation ${ }^{a, b}$

\begin{tabular}{|c|c|c|c|c|c|c|}
\hline & & $\begin{array}{r}2 \% \mathrm{C} \\
\begin{array}{r}\text { then } \mathrm{C} \\
\text { then elec }\end{array}\end{array}$ & $\begin{array}{l}\mathrm{n}\left(\mathrm{CH}_{3}\right)_{2} \\
\mathrm{Tf}_{2}, 4 \% \mathrm{~L}^{*} \text {, } \\
\mathrm{Li},-78^{\circ} \mathrm{C}, 1 \\
\text { hile, }-78^{\circ} \mathrm{C}\end{array}$ & in & & $\begin{array}{l}{ }^{\circ} \mathrm{CH}_{3} \\
\mathrm{r}, 2 \mathrm{~s}\end{array}$ \\
\hline & & & with $\mathrm{C}$ & & without & $\mathbf{I}_{3} \mathbf{L i}$ \\
\hline no. & & electrophile & yield (\%) & C:O & yield $(\%)$ & C:O \\
\hline 1 & $2 r$ & $\mathrm{R}^{\prime} \mathrm{OCOCl}{ }^{c}$ & 48 & $>20: 1$ & $<1^{d}$ & \\
\hline 2 & $2 s$ & $\left(\mathrm{CH}_{3} \mathrm{O}\right) \mathrm{COCN}$ & $72^{e}$ & $>20: 1$ & $<1^{d}$ & \\
\hline 3 & $2 \mathrm{~h}$ & $\left(\mathrm{C}_{6} \mathrm{H}_{5} \mathrm{CO}\right)_{2} \mathrm{O}$ & 73 & $7.3: 1$ & $25^{f}$ & $1: 1.7$ \\
\hline 4 & $2 \mathrm{~h}$ & $\mathrm{C}_{6} \mathrm{H}_{5} \mathrm{COF}$ & 65 & $11: 1$ & $30^{f}$ & $11: 1$ \\
\hline
\end{tabular}

${ }^{a}$ Acylations performed in the absence of $\mathrm{CH}_{3} \mathrm{Li}$ were conducted at $22{ }^{\circ} \mathrm{C}$ for $2 \mathrm{~h}$.

$b_{\text {Each product is formed in } 96 \% \text { ee. }}$

$c_{\mathrm{R}^{\prime}}=(R)$-menthyl.

$d_{\text {Determined by GC-MS analysis. }}$

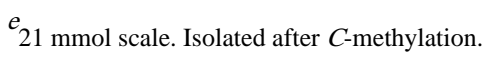

$f_{\text {NMR yields. }}$ 